\title{
PALESTINIAN REFUGEES HOSTING SYRIAN REFUGEES IN LEBANON
}

\author{
Michael SCHULZ, PhD \\ School of Global Studies, University of Gothenburg \\ Email: michael.schulz@globalstudies.gu.se
}

\begin{abstract}
:
Lebanon is receiving most Syrian refugees per capita of all countries surrounding Syria. The most marginalized within Lebanon, the Palestinian refugees that came to Lebanon in 1948 are also hosting arriving Syrian refugees. This study aims to better understand the interplay and interrelations between hosts and refugees. This study is concerned with the overarching question: What is the relationship between the Palestinians hosting the Syrian refugees, and how do they cope with already increasingly narrow resources they have at their disposal, and how is the social relationships between the two refugee groups in Lebanon? Theoretically this study explores and develops a synthesis of a pluralist society model and the ethno-class model, a new approach that best can describe how interrelations in the refugee context in Lebanon are developing. The refugee camp Wavel outside the city of Baalbek in the north serves as case for this study. Semistructured interviews and focal group discussions have been made with both Palestinian hosts, as well as Syrian refugees.
\end{abstract}

Key words: refugees, Lebanon, Palestinian, Syrians, integration, social interrelations

"[T]hey welcomed us. But not any more... Now they see us as taking their jobs, taking their livelihoods... It takes a lot of solidarity if you yourself live below the poverty line," (excerpts from interviews with Syrian refugees in Palestinian refugee camp) ${ }^{1}$

\section{Purpose and Aims}

How do the most marginalized groups in society cope with the influx of refugees, and how do the refugees cope with being placed in the marginalized spaces of society? In Lebanon, the

1 From http://www.dailystar.com.lb/News/Lebanon-News/2017/Jan-10/388616-syria-refugees-test-palestiniansolidarity-in-lebanon.ashx (2017-03-17) 


\section{Security}

most marginalized group since decades, the Palestinian refugees that came to Lebanon in 1948, and are based in refugee camps since then, are hosting Syrian refugees, as the rest of Lebanese society does since 2011.

Lebanon is receiving most Syrian refugees per capita of all countries surrounding Syria. The most marginalized within Lebanon, the Palestinian refugees that came to Lebanon in 1948 are also hosting arriving Syrian refugees since 2011. This study aims to better understand the interplay and interrelations between hosts and refugees. This study is concerned with the overarching question: What is the relationship between the Palestinians hosts and the Syrian refugees, and how do they cope with already increasingly narrow resources they have at their disposal in Lebanon? The article will theoretically explore and develop a synthesis of a pluralist society model and the ethno-class model, a new approach that best can describe how interrelations in the refugee context in Lebanon are advancing. The refugee camp Wavel outside the city of Baalbek in the north of the country has been the locations for this study. Wavel can be seen as a case study of the interrelationship of Palestinian hosts and Syrian incoming refugees.

Since the popular uprising against the Syrian regime began in 2011 (Weyland 2012), Lebanon had to cope with the influx of Syrian refugees, fleeing from the war-torn society. UNCHR estimates that approximately 2 Million Syrians fled to Lebanon, which has around4,4, Mullion Lebanese citizens, and additional $450.000^{2}$ registered Palestinian refugees divided in 12 different camps. In comparison, the Europeans have debated whether the EU societies have reached the roof top for what they believe is what they are able to cope with concerning integration, and claim often that the costs of hosting refugees are too exhaustive for the EU states to handle. Germany and Sweden alone received 64 per cent of Syrian asylum applications in Europe between April 2011 and October 2016 (Amnesty International). At the same time, the larger portion of refugees is hosted by the much economically weaker neighbouring states to Syria, such as Iraq, Lebanon and Turkey. Lebanon is receiving most refugees per capita of all countries, not only in the region, but in the world, and receives continuously Syrian refugees (every fifth is a Syrian refugee in Lebanon. The Palestinian refugees, before the arrival of the Syrians, has been the socio-economically and politically most marginalized non- citizens of Lebanon, and has had large influx of refugees and their host role has become of a more permanent basis. Also, for the Syrian refugees, this new life in the Palestinian camps has with the continuous war in Syria gradually become a long-term life situation. This marginalized life situation between temporary and permanent living conditions, were both hosts and guests are in waiting for a better future situation in their home societies, creates an extraordinary challenging camp life situation.

What are the challenges in this situation for the Palestinians and Syrians living in the Lebanese refugee camps? In what way can Palestinians, located in refugee camps in Lebanon, cope with the immense influx of Syrian refugees? How is it possible to serve as host for Syrian refugees, given the already scarce resources, as well as restrictions in Lebanese society that the Palestinians face in their camp lives (Hanafi et al 2012, Abdulrahim \& Khawaja 2011)? Further, how

2 From UNRWA: https://www.unrwa.org/where-we-work/lebanon (2018-10-15) 
do the Syrian refugees perceive the Palestinians as hosts? How do they find a coping way in the already overpopulated camps, and how do they relate to the Palestinians, as well as the Lebanese society outside the refugee camps?

This study deals with these questions in order to better understand the interplay and interrelations between hosts and refugees with scarce resources. Not least, how Palestinians in Lebanon handle potential conflict issues, as well as integration issues, since the stay of the Syrian refugees have become more of a permanent situation. As indicated above, the Palestinian refugees, located in Lebanon since 1948, do also take a great share in hosting Syrian refugees. The Lebanese society is heavily impacted by the Syrian refugee flow, and in comparison, to any of the EU member states, it is much more affected by them.

\section{State-of-the Art}

From previous research on the Syrian migrants in neighbouring countries (Achilli 2015, Ihlamur-Öner 2013), and in particular in Lebanon, we learn that the Syrian migrants are facing severe challenges. Particularly, studies have shown that women and children are the most vulnerable among the refugees. Women are facing risk of sexual assaults, rapes and gender-based violence, particularly when being alone, or not having their husband with them. Further, the increase of early age marriage has also been noted among Syrian women. (Denman 2013)

Out of the more then a million Syrian refugees, more than half of the migrants are children (UNHCR 2015) and the consequences they face are dreadful. Number of studies focus on the children's humanitarian situation (Jabbar \& Zaza 2014, Naufal 2012), the traumas following the severe war influences, and with negative impact on the psychological health (El-Khani et al 2016, Sirin \& Rogers-Sirin 2015, Özer 2013), and the human security implications (Berti 2015). Other studies focus on the minors' experiences as child soldiers in Syria (Sommerfelt \& Taylor 2015). However, the vast majority of children have traumatized experiences from having to flee the violent war fields, leave home, and go through severe security challenges before arriving to the new host society. Hence, many have focused on the immediate psychological needs of children.

Several studies have also looked at the educational needs of the children, and the challenges of establishing educational training for them (Sirin \& Rogers-Sirin 2015). The Syrian refugee children are risking to loose years of education, and often, when parents face severe economic problems, the dropout rate from education increases dramatically among these children (Charles \& Denman 2013). Some have also focused on the problems that follow with the politics of international aid to Palestinian refugee camps, showing that inflows of resources with the aim to improve the refugees' lives, also has a political underlying objective, i.e. that the Palestinian refugees' should forget their past (Gabiam 2012).

The complexity of the problem increases with the fact that the very interrelationship between the Palestinian hosts and Syrian refugees is an under-researched area. We have little insights of what the hosts in Lebanon think about the Syrian refugee influx in Lebanon. We practically do not have any study on how Palestinian refugees perceive the influx of Syrians. A 
study conducted by the Norwegian Fafo has charted the attitudes of Lebanese citizens towards Syrian refugees, and found that there is a majority that is concerned for the national security situation due to the Syrian refugee inflow, that it will lead to a sectarian violence, and a new civil war also within Lebanon. Lebanese also perceive that the Syrians are taking away the jobs, and housing possibilities from Lebanese, and that the Syrian presence generally has a negative impact on the overall economic situation. Also, a majority of the Lebanese consider that the Syrian unfairly gain support. (Christophersen et al 2013)

Although we have knowledge about the Lebanese host society at large and its interplay with refugees (see for instance Lopez-Rodriguez et al 2014), we have barely nothing on how Palestinian refugees and the Syrian refugees inside the Palestinian camps interplay, and how do they find ways to live together from a long-term perspective. The Palestinians in particular, have a long-term experience of being permanently placed in refugee camps, seen as temporary, and making the dream to return to Palestine part of their life. The way Palestinians cope and interact with the Syrian refugees is an under-researched area.

In sum, despite important insights from above studies on Syrian refugee's immediate crisis situation in Lebanon, as well as in neighbouring countries, we still lack studies that take a broader, as well as long-term perspective, of the increased permanent living situation of refugees in Lebanon, and in particular inside Palestinian refugee camps. Due to the long-term presence, leading to a permanent living situation for the Syrian refugees, we need to understand how marginalized groups, like the Palestinian refugee's cope going from immediate crisis management to long-term integration issues due to the increasing permanent presence of Syrians, despite scarce resources. Further, we need to use an intersectional approach, in particular the social categories of gender and age (incl. minors) in order to better understand what the long-term consequences will be for the Syrian refugees that are forced to stay in Lebanon for many years to come. Finally, there are few studies that have a broader, or holistic, approach, with the aim to cover a range of aspects that usually are used in integration research. Below follows a description on how this model for analysing integration has been applied in the case of how long-term refugees host relatively recent arrived refugees.

\section{Contribution of this study}

Generally, we have little previous research on insights on how marginalized migrant groups are coping between segregation and integration. This study argues that great refugee influx in host societies over a longer period of time, in which the forced migration situation gradually changes to a permanent unwanted away from home, also transforms the integration and societal character of the host society. It becomes both an empirical as well as a theoretical issue to find out what ethnic relations that develop over time, and what kind of integration/segregation we can identify. This study has explored theoretically and developed a synthesis of a pluralist society model and the ethno-class model, a new approach that best can describe how interrelations in the refugee context in Lebanon are developing. The Palestinians and Syrians interrelations in the camp context 
are discussed below. While the ethno-class approach predicts further conflict and confrontation between groups in society, the pluralist approach describes these tensions as existing but can also slowly decrease over time. The argument is that refugees that are marginalized, do find ways over time to gradually, although slowly, are finding ways to cope with these extra-ordinary challenges.

Despite their weaker socio-economic and political positions in society, they do invent ways, and are able to build a new (temporary) home.

The project design addresses one important aspect of how socio-economic weaker groups in war-torn societies cope and manage to host refugees. Despite the hardships, the Palestinians share with the Syrian incoming refugees the experience of having to flee the home country, as well as being forced to begin a new life in a host country. Also, the unknown future, if or when a return is possible to the homeland, is also something the Palestinian hosts and Syrian refugees share. Hence, the project will on the one hand give some important insight on how the most marginalized groups in an already overburden society as Lebanon is, manage to cope with conflicts among them, and in particular related to integration issues. It also will show, what particular vulnerable areas and challenges, these marginalized groups face in their attempts to solve the day-to-day living conditions. In addition, it will identify possible stumbling blocks and potential solutions to challenges in terms of distribution of (scarce) resources, education, co-habitation, and integration in times of volatile security context.

\section{Methodological approach}

As stated, the main objective of this study was to inquire empirically as well as understand theoretically, in what way the Palestinian refugees cope with the role as hosts of Syrian refugees. Also, the interplay between Syrian refugees and the Palestinian hosts is in focus of the study. The purpose of this study was to come a little bit closer to an understanding of how hosts - being themselves refugees, cope with receiving people who are fleeing from war torn contexts, and how both hosts and refugees reason about the new life situations. Not least in terms of short versus long-term planning, where both Palestinian hosts and the Syrian refugees know that a return to Syria is seemingly not imminent. At the same time, the pressure to cope with the harsh new living conditions cooperation between hosts and refugees around the narrow resources is necessary, but also basis for tensions and conflicts.

The analytical model has previously been developed by Schulz's study of integration (Schulz 1996), partly inspired by Yinger (1981). In order to analyse the interplay and interaction between the Palestinians and the Syrian refugees four overarching aspects have been examined so as to evaluate how far the integration is taking place, and/or to what extent the two groups remain within their own spheres. These aspects cover the following sub-processes: 1. (Socioeconomic integration) the level of integration (structural aspects, i.e. the level of access to various socio-economic arenas, such as health care, education, political decision-making arenas etc.) 2. (Amalgamation) the extent to which new close relations develop (i.e. the extent of inter-group 


\section{Securiaty}

friendships and marriages); 3. (Acculturation) the extent to which acculturation takes place (cultural aspects, i.e. the extent of adopting new customs within the host society versus preserving the own groups' customs), and 4. (Identification) the extent of the refugees' identification with the host society, as well as the readiness of the host society to accept the newcomers (psychological, i.e. ways and extent of identification with the hosts society),

There is an interrelationship between these above-mentioned sub-processes in so far that each affects the strength of the other. The reciprocal process-plural acculturation-is a process whereby intra-societal differences are maintained and created around subcultural groups (Schulz 1996, Yinger 1981). These sub-processes affect the extent of integration-segregation continuum. The concept of integration is usually referred to the extent of how far the process of integration in socio-economic terms (i.e. income, education, living standard, access to the social welfare system etc.) has been reached, or the reverse process of segregation, when the integration has failed and instead slowed down or even reversed. With the Class perspective, the process of integration is rather seen as a 'false ideology', which in the Lebanese context is used to either describe how the dominant Lebanese groups position relate hierarchical in relation to the vis- the camp Palestinians, and even further vis-à-vis the Syrian refugees inside the Palestinian camps. It can also be seen as an ideology of the dominant group to maintain control over the subalterns (the Syrian refugees). With a Pluralist approach, similar arguments are put forward, but dominance is seen as gradually decreasing. The limitations with the Class perspective lies in the fact that improvements can not merely be nullified by claiming the attempts of the dominant ethno-class to maintain power. The Pluralist approach emphasizes precisely these differences between ethnic groups but also risks to neglect the possibility for integration of various groups in the camp society, by emphasizing the conflict relations more. Hence, if all four-sub processes are weak, we can speak of an ethno-class camp society, however, if some of the sub-processes increases, we have more of a pluralist society with gradual improvements. However, due to the camps sub-ordinated position within Lebanese society, we cannot speak of any dramatic integration with the larger Lebanese society. At best, we can speak about gradual integration of Syrians into the camp life, but still in a process between integration and segregation.

\section{Data collection}

During the period of my stay in Lebanon for a longer period during 2012-2013, several visits were made to the refugee camp Wavel, and have also been followed up at several times since then (the most recent in October 2018). From these experiences, I understood that working with sensitive issues, one must build upon solid knowledge about the specific cultures of the research context. Dealing with sensitive issues such as host-refugee relations requires in-depth knowledge, positions of trust, entry-points, social networks and careful manoeuvres in order to prevent doing any harm to people in the refugee camps, taking also into consideration the overall state/societal context of the country/region in question. Besides the number of years of field research I have had in the Middle East, I have over the last five years also built close relations with people living in 
the Palestinian refugee camp Wavel outside Baalbek in the north of Lebanon. Although my main stay in Lebanon 2012-2013 was in the Beirut area, and despite relatively good contacts developed also in the Sabra and Shatila camps in Beirut, I have decided to abstain from doing research in those camps. The reason to this is that it is one of the most over-researched research geographical spots, most likely the most over- researched Palestinian refugee camp in the world. One must be aware that camp residents are not '...just passive subjects (or victims) of the practices and interests of outside researchers' (Sukarieh \& Tannock 2012:13). Researchers simply have too much affected the lives of the residents of the Sabra and Shatila camps. As researchers, we rather prefer to be in a camp, where our presence is not seen with critical and sceptical eyes.

Hence, the refugee camp Wavel has been the empirical location for this study. This camp has not been exposed for much research. The Wavel camp has a bit less than 10000 Palestinian refugees, but has since 2011 been exposed to inflows of Syrian refugees. The camp has always been in a relatively poorer socio-economic situation in comparison to other camps in Lebanon. Hence, the few available resources that have to be shared with the incoming Syrian refugees makes the locations as extra-ordinary show case for studying the interplay between hosts and refugees under harsh livelihood conditions.

\section{Data analysis}

In order to collect systematic relevant data for the model of analysis, it would have been useful, and more valid, to launch a statistical questionnaire with a larger number of Palestinians and Syrians in the camp. However, due to the security situation in Lebanon, and also in the camp itself, this has so far not been a realistic option. The study has, instead, primarily applied a qualitative approach, and mainly collected data via semi-structured interviews with people living in the camp, in combination with observations. In order to gain some indicative data for the analytical model described above, one had to approach both Palestinians and Syrians and let them describe more freely their thoughts of the socio-economic situation in the camp, the extent and quality of contact with the out- group, the freedom of choice about their way of life, and the way they identify within their own refugee group, as well as in relation to the Palestinian host society. For this purpose, some semi- structured interviews have been made with both Palestinian hosts, as well as Syrian refugees (about equally amount of men and women). Absolute caution was taken with all, and the approach had to be built upon a trust building process, voluntary participation, and consent of each person interviewed or conversed. Due to the fragile security situation, no voice recording was made, but notes were made after the interview, and all are anonymous. Some observations have been made, all in order to observe the ways of lives and interactions between Palestinians and Syrians in the camp, and also participate in religious, festivals, and other events, enabling close range studies. 


\section{Findings}

Empirically, the initial findings showed that conflicts were more overshadowed by solidarity and trust in 2012, as well as capacities to help each other developed between the Palestinians and Syrians, despite scarce resources. However, with time, and increased influx of refugees, and several years later, indicated that the more permanent living situation in the camp had created increased tension between the two groups. The on-the-ground field-work in the camp allowed to get first-hand information and insight of successful cooperation on the daily lives the host Palestinians and Syrians shared. Despite the lack of many basic resources, as well as high density of people living in the low standard housing options, both hosts and refugees, tried to cope in a cooperative manner. The observations and talks with them gave insights for how people find ways to cope also under severe circumstances, as well as cooperate and help each other. However, these harsh living condition affect the relations over time, and change views and visions between the hosts and the refugees

\section{Socio-economic integration}

The level of the structural integration of the Syrian refugees in Lebanon seems to be low, and reports indicate that they also become poorer and more dependent on international aid $\left(U N C H R^{3}\right)$. Further, the report underlines food insecurity as sever, and many are below the poverty line. Recent reports from Human Rights Watch even witness about mass expulsion of Syrians back to Syria (Human Rights Watch report ${ }^{4}$ ), which can be a further sign of the increasing crisis between hosts and refugees inside Lebanon. The camp life in Wavel is a further example of this demanding situation, since the Palestinian "host" refugee's also have a difficult situation, and are relying on UNRWA support. Housing situation in the camp is difficult, and families, not seldom in the size of 6-8 members, have to share very small living areas, often one single room of 8-15 square meters). The life in the camp is particularly harsh in the winter, not least due to limited heating options, and with cold winters. In Wavel, several Syrian families had to walk for 10 minutes in order to reach fresh water stations. The extent the Syrian refugees can participate in the political decisionmaking arenas is very low. The educational situation is critical, and the camp has two schools with a school aged population that nearly constitute a third of the camp habitants. This also leads to high-drop out rates. Further, the employment opportunities are low, and makes the refugees even more dependent on the UN. Since many of the Syrian refugees, also are including Palestinian refugees from Syrian camps, a certain to acceptance from the Palestinian host society members thus have granted the Syrians free and equal access to the existing educational, professional and institutional arenas. However, the limited sources create tensions, and discussion of how

\footnotetext{
$\overline{3}$ http://www.unhcr.org/news/briefing/2018/1/5a548d174/survey-finds-syrian-refugees-lebanon-poorervulnerable-2017.html (accessed 29th May, 2018).

${ }^{4}$ https://www.hrw.org/report/2018/04/20/our-homes-are-not-strangers/mass-evictions-syrian-refugees-lebanesemunicipalities
} 
the distribution of resources between the two groups - the Palestinians and Syrians, in the host society, best can be made often was on the daily agenda. High extent of grievance was part of the everyday life and occurred so often that it had to be, and had to be handled regularly. The extent of socio-economic gaps and power disparities between the two groups created some form of inequality feeling between them the longer time went.

\section{Amalgamation}

The extent of social interaction between various groups in a society may provide a picture of how individuals cope with each other in society. In Wavel, Syrian refugees are aware of their distinct different identity then the Palestinian identity, although both groups do feel commonality in their refuge status. Naturally, the Palestinians refugees coming from Syrian camps, do feel more commonalities with their Palestinian sisters and brothers in Lebanon. However, the Lebanese Palestinians, still often refer to them as "the Syrians". Although in-group relations are the strongest, and also from a security point of view, the family structures, the extended Hamuleh network, are the primary safety net for all. Friendship relations between Palestinians and Syrians do also develop, despite that they live together separately on the camp. In the interviews, they also gave a few examples of "inter-ethnic" marriages between them.

\section{Acculturation}

The notion of acculturation refers to the extent an individual is adopting host societies 'new customs' or 'keeps' old customs and values. Do most refugees accept the formal lifestyle of that particular society? From both observations, and in interview situation, one can see that the living styles are very much similar and can thereby to a great extent have individual 'home' habits, costumes, values and way of life, without risking to be seen to challenge the broader life in the camp. Syrian refugees, but also Palestinian hosts, in that sense do not feel an urge to transform their ways of living as a result of the arrival of the Syrians. They often share similar customs, dress codes (although smaller variations exist), speak the same language (although with dialectic variations of Arabic), and the same religion (all are Muslims). Instead, were difference exist, they have been open to share and learn experiences from each other. For instance, people listen to each other's music, and even take up their smaller differences in food traditions. In other words, many similar traditions exist, and rather the Palestinians and Syrians have respect to most of those cultural differences that exist. However, one of the recent more problematic challenges inside and outside the camp camps in Lebanon is related to the many unregistered illegal Syrian refugee families who try to marry away their daughters to locals in order to gain the right to stay. This has increased polygamy, and strengthened the patriarchal structures, and is seen with critical eyes by the Palestinians also in the Wavel camp. Hence, this has caused tensions between the two groups, and the impact on acculturation. 


\section{Identification}

When asked about the extent Syrians and Palestinians are identifying with their own group identity, and to what extent they feel commonality with the out-group (as refugees and other identities of being marginalized and away from "home"), a mixed picture comes forward. The emotions and sentiments of collective group belonging. Also varies depending on what relation, situation, and context the meetings take place. In other words, the in- and out-group identification is fluid and both Palestinians and Syrians do shift in how close they feel to the "other". Particularly Palestinian Syrian refugees have a slightly easier, compared to the non-Palestinian Syrians, to receive acceptance from the host society. At the same, the camp Palestinians do also perceive the arrival of Palestinian Syrians as members of a Syrian diaspora. Also, on an overarching level Palestinians and Syrians find common identification around their common experience as being refugees in a host (and often not too welcoming) society. The "us" and "them" dichotomization between camp Palestinians and the Syrians has increased with the increased socio-economic difficulties.

\section{Conclusion}

The qualitative data discussed in relation to the analytical indicators of integration (socioeconomic integration, amalgamation, acculturation, and identification) has shown that the Syrian refugees can be placed between the pluralist and the ethno- class models. The refugee life in Lebanon is very much a segregated existence, but within the camp we can see that Syrians do have a subaltern position, but relatively, also have gained some increase of the examined four- subprocesses (acculturation and identification in particular). With high levels of all four indicators, gives support for an ongoing gradual integration, however, since Syrians do not have citizens status in Lebanon, they jointly with the Palestinians, will have a distinct system within Lebanon (as refugees), and we can thereof at best speak more of a pluralist society. Over time, since the study began (in 2012) we can see an increase of lack of basic socio-economic resources, which also has created more tensions between Palestinians and Syrians. This indicates a decrease of the support of the pluralist approach. Further, it also implied an increase of the ethno-class model. We can see the risk that includes escalated conflicts of scarce resources between the most marginalized groups. This was a qualitative study, that could give us some indications of what the situation in the interrelationship between two marginalized groups in Lebanon can be. When the security situation allows, more systematic quantitative questionnaires could be applied in order to take some more precise measures of the sub-processes, and perhaps contribute to theorize and develop the societal model that seemingly is placed somewhere between the ethno-class and pluralist models, but closer to the segregation side on the integration-segregation continuum. 


\section{References}

1. Abdulrahim, S. \& Khawaja, M. (2011), 'The Cost of being Palestinian in Lebanon', Journal of Ethnic and Migration Studies, Vol 37, No. 1, pp.151-166.

2. Achilli, L. (2015), Syrian refugees in Jordan: reality check, Migration Policy Centre Research Report 2015/02.

3. Abdulrahim, S. \& Khawaja, M. (2011), 'The Cost of being Palestinian in Lebanon', Journal of Ethnic and Migration Studies, Vol 37, No. 1, pp.151-166.

4. Achilli, L. (2015), Syrian refugees in Jordan: reality check, Migration Policy Centre Research Report 2015/02.

5. Berti, B. (2015), 'The Syrian Refugee Crisis: Regional and Human Security Implications', Strategic Assessment, Vol. 17, No.4, pp. 41-53.

6. Christophersen, M., Lui, J. Thorleifsson, C. Tiltnes, Å. A. (2013), Lebanese attitudes towards Syrian refugees and the Syrian crisis. Results from a national opinion poll. Implemented 15-21 May, 2013, Fafo-paper 2013-13.

7. Denman, K. (2013), 'Syrian and Palestinian Syrian Refugees in Lebanon: the plight of women and children', Journal of International Women's Studies, vol. 14, Issue 5, pp. 96-111.

8. El-Khani, A., Ulph, F., Peters, S. \& Calam, R., (2016), 'Syria: the challenges of parenting in refugee situations of immediate displacement', in Intervention, Vol. 14, Issue 2, pp. 99 - 113. doi: 10.1097/WTF.0000000000000118

9. Fiddian-Qasmiyeh, E. (2016), 'Refugees hosting refugees', Forced Migration Review, 53 (Oct 2016): 25-27.

10. Gabiam, N. (2012), "When "Humanitarianism" becomes "Development": the Politics of International Aid in Syria's Palestinian refugee camps, American Anthropologist, Vol. 114, No. 1, pp. 95-107.

11. Hanafi, S., Chaaban J., \& Seyfert, K, (2012), Social Exclusion of Palestinian Refugees in Lebanon: Reflections on the mechanism that cement their persistent poverty', Refugee Survey Quarterly, Vol. 31, No. 1, pp. 34-53.

12. Ihlamur-Öner, S. G. (2013), 'Turkey's Refugee Regime stretched to the limit? The case of Iraqi and Syrian refugee flows', Perceptions, Vol. XVIII, No. 3, 191-228.

13. Jabbar S. A. \& Zaza, H. I. (2014), 'Impact of conflict in Syria and on Syrian children at the Zaatari refugee camp in Jordan', Early Child Development and Care, Vol. 183, Issue 9-10, http://dx.doi.org/10.1080/03004430.2014.916074

14. Lopez-Rodriguez, L., Navas, M., Cuadrado, I., Coutant, D., and Worchel, S. (2014), 'The majority's perceptions about adaptation to the host society of different immigrant groups: The distinct role of warmth and threat', International Journal of Intercultural Relations, Vol. 40, pp. 34-48.

15. Naufal, H. (2012), Syrian refugees in Lebanon: the humanitarian approach under political divisions, Migration Policy Centre Research Report 2012/2013. 


\section{Security}

16. Özer, S. Sirin, S. \& Oppedal, B. (2013), Bahcesehir Study of Syrian refugee children in Turkey, Bahcesehir University report.

17. Schulz, Michael, 1996, Israel between Conflict and Accommodation. A Study of a Multi-Melting Pot Process, Cöteborg: Padrigu PhD Thesis Series.

18. Sirin, S. R. \& Rogers-Sirin, L. (20), The educational and mental health needs of Syrian refugee children, Washington: Migration Policy Institute.

19. Sommerfelt, T. \& Taylor, M. B. (2015), The big dilemma of small soldiers: recruiting children to the war in Syria, Norwegian Peacebuilding Resource Centre Report (NOREF), NOREF Report 2015, February.

20. Sukarieh, M. \& Tannock, S. (2012), 'On the problem of over-researched communities: the case of the Shatila Palestinian Refugee Camp in Lebanon', Sociology, 0(0), pp. 1-15.

21. Thorleifsson, C. (2014), 'Coping strategies among self-settled Syrians in Lebanon', Forced Migration Review, 47 (Sep 2014), pp. 23-25.

22. Weyland, K. (2012) 'The Arab Spring', Perspectives on Politics, 10: 4 (Dec.) pp. 917-934. Yazgan, P., Utku, D. E., and Sirkeci, I. (2015), 'Syrian Crisis and Migration', Migration Letters, Vol. 12, No. 3, pp. 181-192.

23. Zetter, R. \& Ruaudel, H. (29), 'Development and protection challenges of the Syrian refugee crisis', Forced Migration Review, 47 (Sep 2014), pp. 6-10. 